\title{
Determinants of the Level of Care Provided for Various Types and Sizes of Dogs in New Providence, The Bahamas
}

\author{
William J. Fielding ${ }^{1}$
}

\begin{abstract}
This paper reports the level of care offered 424 dogs, classified as small dogs, large dogs, pit bulls and potcakes (the colloquial name for the local mongrel) in New Providence, The Bahamas. Levels of care that meet the legal minimum -food water and shelter- as well as care considered essential and enriched in The Bahamas were less common for large dogs than small dogs. Small dogs tended to get more care than other dogs and so were at lowest risk of being neglected. It is suggested that the size of the dog is an important factor which determines the level of care provided. Pit bulls generally received similar care to potcakes which are often considered neglected. Large dogs were more likely to be kept outside and less likely to be allowed inside the home than small dogs. It is conjectured that in many instances the level of care offered constitutes partial abandonment due to a lack of interaction between caregivers and their dogs.
\end{abstract}

The neighbour, them, don't take care of them. Usually when they're small they show them off and they take good care of them. As they get [a] little older, and as they grow and get bigger they start to neglect them (Butler, Carole, Samuels, \& Vanderpool, 2001, p. 20).

\section{INTRODUCTION}

The care offered dogs has attracted the interest of many researchers. Matter and Daniels (2000) have described the cultural and environmental factors which influence the ways dogs are kept around the world. These factors include local variations in care, not only between countries but also within countries, e.g., Poss and Bader (2007) have studied variations in levels of dog care in the
United States. In some situations dogs are considered a public health hazard, particularly when rabies is in the dog population (Macpherson, Meslin \& Wandeler, 2000) while other researchers, such as Beck and Katcher (1996) have focused on the beneficial effects of keeping dogs. The care of dogs, or the reasons for keeping dogs, is a cause for concern, particularly when linked with deviant behaviours (Fielding \& Plumridge, 2010), and has been the subject of

\footnotetext{
1 William J, Fielding, Director of Planning, The College of The Bahamas.

E-mail: wfielding@cob.edu.bs

Acknowledgements: The focus groups were organized by Faith Butler, Cristin Carole, Denise Samuels and Joan Vanderpool. Amy Hanna reviewed the advertisements for pets in The Nassau Guardian. The author is grateful to students at The College of The Bahamas for participating in the focus groups held in 2001 and the SOS 200 class of Fall 2008 for collecting the data for the survey and for their input into the questionnaire. The HITS@ inventory was used with the permission of Kevin Sherin.

How to cite in APA 7th ed. style: Fielding, W. J. (2010). Determinants of the level of care provided for various types and sizes of dogs in New Providence, The Bahamas. The International Journal of Bahamian Studies, 16, 13-26. https://doi.org/10.15362/ijbs.v16i0.119
}

CW.J. Fielding, 2010. Journal compilation @ The International Journal of Bahamian Studies, 2010. 
study by researchers from around the world and diverse backgrounds (Ascione, 2008).

However, as noted by Shore, Riley and Douglas (2006) few studies have looked at how we care for animals from the point of view of the latter. Do we care for pets in ways that are beneficial to them? Fielding and Plumridge (2005) have suggested that in The Bahamas the type of dog (pure-breed, mixed-breed and local mongrel) affected the level of care, with those of higher monetary value (pure-breeds) receiving more care and the less valuable (mongrels) receiving less care. Shore (2005) found that most pets received components of essential care but when caregivers were more attached to their pets they received more care. Shore et al. (2006) also found that yard dogs received less care than house dogs in the United States. In The Bahamas, the care offered house or inside and yard or outside dogs also varies. In The Bahamas dogs kept outside are less likely to be neutered than those kept inside the house (Fielding \& Plumridge, 2005); further, inside dogs tend be regarded as companions while dogs kept outside tend to be working dogs, being expected to protect the home.

In The Bahamas, Fielding, Mather and Isaacs (2005) noted that house dogs are smaller than yard dogs. This may be due to a number of reasons, including the lack of space in small homes to accommodate large dogs and we could conjecture that small dogs are seen as less threatening than large dogs and so are allowed to be closer to both adults and children. Small dogs may be regarded as puppies which never grow up and so remain cute and easy to care for. While Bahamian households may allow puppies inside the home, as they grow older (and larger) they are at risk of being moved outside the home. As one college student said, "If I would have a pet, it would be something small" and another "The dogs...they used to stay inside and afterwards they became a nuisance ...they have a doghouse outside" (Butler et al., 2001, p. 15).

Bahamian law requires caregivers to provide, food, water and shelter to their animals under laws relating to animal care which were last modified in the 1920s (Penal Code, 1927). The age of the laws relating to dog care means that there are some legal aspects of care which appear antiquated compared to other Caribbean islands, such as Antigua and Barbuda which passed its Dogs Registration and Control Act in 2006. As an illustration, according to the Bahamas Dog Licence Act (1942), it is legal for a licensed dog, which is not on heat, to roam the streets during the day. Although the laws on animal care may be old, they do provide a frame of reference as to the minimum elements of care which must be provided. However, Fielding (2007) has found that not everyone knows the laws with respect to animal care, so the care that some dogs receive may not meet the minimum required by law.

The purpose of this paper is to examine how the size and type of dog may be linked with care and interactions between caregivers in The Bahamas. Given the population structure of The Bahamas, the study could also be considered as a case study of an Afro-Caribbean community. We will highlight two types of dogs: potcakes, the vernacular name for the local mongrel, as these dogs are known to receive less care than other dogs, and pit bulls, primarily because they have been responsible for fatal attacks on people in The Bahamas.

\section{Method}

Students at The College of The Bahamas aged 18 or over living in dog-keeping households constituted the target population for the survey. Students of a research methods course visited classes and asked students to participate in the study. Participation was voluntary and each respondent signed an informed consent form. The questionnaire was a self-completion form and responses were confidential. The study was carried out with permission of the Office of Research, Graduate Programmes and International Relations of The College of The Bahamas.

The starting point was the classification of care proposed by Shore et al. (2006). They identified four levels of care: essential, standard, enriched and luxury. With essential care, "the owner provides for the basic physical needs of the pet"; with standard care, the "owner provides care and attention usually associated with pet ownership"; with enriched care, the "owner provides attention, activities and/or resources that create a more stimulating environment for the pet" and with luxury care the "owner provides indulgences that 
may be superfluous, extravagant, or expensive" (Shore et al., 2006, p. 327).

While the components of care in each of these categories of care may adequately describe essential, standard, enriched and luxury in the context of the United States, community differences required that some components be added to reflect caring practices in The Bahamas. Fielding et al. (2005) have found that it is common for caregivers to allow dogs onto the street to wander unattended and it is unusual for dogs to sleep in a caregiver's bedroom. We also note that for a care activity to be beneficial, the components need to be not only provided but offered with the necessary frequency (MorrowHowell, Proctor, \& Dore, 1998). In The Bahamas, the fact that residents feed dogs that they do not claim to own (Fielding et al., 2005) suggests that the regularity of feeding by some caregivers may be inadequate.

In this study, we indicate which components have been added to those of Shore et al. (2006) and add the suffix BS (the internet domain name for The Bahamas) to each of Shore's terms to indicate that our classifications are different to hers and may only be appropriate to The Bahamas. These additional elements also indicate aspects that college students, who provided input on the content of the survey form, felt were too important to be omitted.

It might be argued that some components, particularly those in the luxury category may not be suitable for the Bahamian context, however, they were still asked as the responses provide a baseline from which future changes in care can be assessed. Additional questions concerning household-dog interactions were added based upon topics included in DeViney, Dickert and Lockwood (1983). The HITS $\subseteq$ inventory, developed by Sherin, Sinacore, Li, Zitter and Shakil (1998) for identifying victims of domestic violence, was used to determine if domestic violence was present in the household as domestic violence has been linked to the care and treatment of animals (Ascione \& Arkow, 1999).

As in Shore et al. (2006), when participants lived in homes with several dogs they were asked to choose one dog and answer the questions as they related to that selected dog. Based upon the self- reported breed or type of dog, the sample allowed dogs to be divided into four classes: large dogs (pure-bred dogs, which may or may not be pedigreed, or look like a pure-bred dog, other than small breeds), pit bulls, small (toy) dogs (Shih Tzu etc., breeds or mixes which would be expected to also be small in size) and potcakes.

The largest dogs included in the small dogs classification would have been spaniels and sausage dogs, based on the information provided. Typically, potcakes are a medium-sized dog (Fielding et al, 2005). Pit bulls were distinguished from other dogs because they have been implicated in all the reported fatal dog attacks on humans in The Bahamas (Burrows, Fielding \& Mather, 2004) and so their care is of particular interest to society. Pit bulls have been associated with fatal attacks on humans in the United States (Delise, 2002) and in some instances there is a stigma associated with keeping pit bulls (Twining, Arluke \& Patronek, 2001). Potcakes were highlighted as their care has been noted as a cause for concern in earlier studies (Fielding, 2007). The percentages given in the results are those of dogs within a particular class of dog (based on the size/type) and the number reported is the observed number of respondents reporting that attribute in their selected dog. We assume that each respondent represented a unique household.

\section{Results}

While 477 students participated in the study, information about the breed/type of dogs was gathered on only 424 dogs. Not all respondents answered every question so 424 is the maximum sample size. Potcakes were the most commonly reported dogs (165), then large dogs (105), small dogs (101) and pit bulls (53). Shih Tzus (60) were the most common small dog. Large dogs were dominated by Chow-Chows (22), Rottweilers (19) and German shepherds (15). The ages of 218 dogs were reported. The median age of the four types of dogs was similar (3.0 years, Kruskal-Wallis test, $d f=3, n=201, p=0.083$ ).

\section{Components of care}

When considering the three components of care required by law-food water and shelter-potcakes were least likely to receive all three components, $63.0 \%$ (104 dogs), compared to 68.6\% (72 dogs) 
for large dogs, 73.6\% (39 dogs) for pit bulls and $81.2 \%$ (82 dogs) for small dogs, Chi-squared $=$ $10.3, p=0.016, d f=3, n=424$. The odds ratio of large dogs receiving all components compared to small dogs was 0.51, 95\% CI [0.26-0.96]. Pit bulls were no more likely than potcakes to receive these components of care, odds ratio $=1.63$, CI [0.82-3.25]. A logistic regression, to see if the provision of legal care was linked to type of dog, if the dog spent most of his time outside the home and if the dog was kept as a companion, found none of these components to be statistically significant $(p>0.05)$.

\section{Essential Care}

The components of essential care-Bahamas (ECBS) showed that these were more commonly associated with small dogs and least common with potcakes (Table 1). Potcakes were the most likely dog to be allowed access to the street. If being allowed to roam the street is considered to be a negative component of care, the percentage of respondents reporting nine or more ECBS was $50.5 \%$ (48 dogs) for small dogs, 40.6\% (39 dogs) for large dogs, 33.3\% (17 dogs) for pit bulls and 21.6\% (32 dogs) for potcakes, Chi-squared = 23.1, $n=390, d f=3, p<0.001$. Large dogs were less likely than small dogs to receive this level of care. Odds ratio of large dogs receiving nine or more components, compared to small dogs was 0.40, CI [0.23-0.71]. Also, these observations suggested that potcakes were most likely to be neglected, odds ratio of potcakes receiving nine or more components, compared to small dogs was 0.27 , CI [0.15-0.47]. Pit bulls were just as likely to receive these components of care than potcakes, odds ratio $=1.81$, CI [1.90-3.66]. A logistic regression, to see if the provision of essential care was linked to type of dog, if the dog spent most of its time outside the home and if the dog was kept as a companion, found that the type of dog (Wald statistic $=14.7, d f=3, p=0.002$ ) was the only component to be statistically significant.

Table 1

Essential Care - Bahamas (ECBS) Components Offered Different Types of Dogs

\begin{tabular}{|c|c|c|c|c|c|c|c|c|c|c|}
\hline & \multirow[b]{2}{*}{ Component } & \multicolumn{2}{|c|}{ Small dogs } & \multicolumn{2}{|c|}{ Large dogs } & \multicolumn{2}{|c|}{ Pit bull } & \multicolumn{2}{|c|}{ Potcake } & \multirow{2}{*}{$x^{2}$} \\
\hline & & $\mathrm{n}$ & $\%$ & $\mathrm{n}$ & $\%$ & $\mathrm{n}$ & $\%$ & $\mathrm{n}$ & $\%$ & \\
\hline & Has access to shelter & 92 & 97 & 95 & 86 & 48 & 92 & 135 & 82 & 0.002 \\
\hline$E$ & Fed bought dog food & 89 & 95 & 100 & 92 & 48 & 91 & 110 & 68 & $<0.001^{*}$ \\
\hline & Fed at least once a day & 87 & 95 & 100 & 93 & 47 & 94 & 135 & 87 & 0.10 \\
\hline$E$ & Has access to water at all times & 87 & 92 & 100 & 90 & 48 & 91 & 150 & 91 & 0.94 \\
\hline$E$ & $\begin{array}{l}\text { When everyone is away from home for more } \\
\text { than one day, the dog is cared for }\end{array}$ & 85 & 90 & 98 & 89 & 46 & 87 & 127 & 78 & 0.026 \\
\hline & The person who should feed the dog does so & 94 & 90 & 98 & 89 & 47 & 89 & 137 & 85 & 0.56 \\
\hline E & Has a veterinarian & 84 & 88 & 77 & 71 & 30 & 58 & 60 & 37 & $<0.001^{*}$ \\
\hline$E$ & $\begin{array}{l}\text { When prime caregiver is ill, someone cares } \\
\text { for the dog }\end{array}$ & 83 & 88 & 98 & 88 & 45 & 85 & 136 & 82 & 0.45 \\
\hline E & Acts differently when sick & 82 & 88 & 95 & 87 & 42 & 79 & 119 & 74 & 0.013 \\
\hline$E$ & The dog is current on its rabies shot & 78 & 82 & 86 & 80 & 42 & 79 & 83 & 51 & $<0.001^{*}$ \\
\hline & The dog is allowed to roam on the street & 15 & 16 & 16 & 15 & 8 & 15 & 71 & 44 & $<0.001^{*}$ \\
\hline
\end{tabular}

Note: E: Indicates items on Shore et al. (2006) list.

* Indicates significance at the 5\% level with a Bonferroni adjustment

\section{Standard Care}

Potcakes were least likely to receive eight or more of the 16 standard components of care-Bahamas
(SCBS). As shown in Table 2, 33.8\% potcakes (46 dogs); pit bulls 55.1\% (27 dogs); pure-breeds $74.5 \%$ (70 dogs); small dogs $84.1 \%$ (74 dogs) received standard components of care, Chi- 
squared $=68.2, d f=3, n=367, p<0.001$. (In calculating this component we do not consider chaining to be necessarily an undesirable component, although in some circumstances it may be so). Compared to small dogs, potcakes were less likely to receive eight or more components, odds ratio $=0.10$, CI [0.05-0.19]. Compared to small dogs, large dogs were just as likely to receive this level of care, odds ratio $=$ 0.55, CI [0.26-1.15]. Pit bulls were more likely to receive these components of care than potcakes, odds ratio $=2.40$, CI [1.23-3.67]. A logistic regression, to see if the provision of SCBS was linked to type of dog, if the dog spent most of its time outside the home and if the dog was kept as a companion, found type of dog (Wald statistic $=$ 31.3, $d f=3, p<0.001)$ and the dog spending most of its time outside the home (Wald statistic $=18.4$, $d f=1, p<0.001)$ to be statistically significant.

Table 2

Standard Care - Bahamas (SCBS) Components Offered Different Types of Dogs.

\begin{tabular}{|c|c|c|c|c|c|c|c|c|c|c|}
\hline & \multirow[b]{2}{*}{ Component } & \multicolumn{2}{|c|}{ Small dogs } & \multicolumn{2}{|c|}{ Large dogs } & \multicolumn{2}{|c|}{ Pit bull } & \multicolumn{2}{|c|}{ Potcake } & \multirow{2}{*}{$\begin{array}{l}X^{2} \\
p=\end{array}$} \\
\hline & & $\mathrm{n}$ & $\%$ & $\mathrm{n}$ & $\%$ & $\mathrm{n}$ & $\%$ & $\mathrm{n}$ & $\%$ & \\
\hline S & In the last year, the dog has visited the vet & 89 & 94 & 81 & 73 & 33 & 64 & 71 & 44 & $<0.001^{*}$ \\
\hline$S$ & Receives heartworm prevention medication & 86 & 91 & 90 & 83 & 41 & 77 & 81 & 51 & $<0.001^{*}$ \\
\hline S & The pet receives medication to prevent fleas and ticks & 84 & 89 & 96 & 87 & 39 & 74 & 103 & 63 & $<0.001^{*}$ \\
\hline$S$ & $\begin{array}{l}\text { When the family is home, the dog is with them most of } \\
\text { the time }\end{array}$ & 79 & 85 & 73 & 66 & 20 & 38 & 77 & 48 & $<0.001^{*}$ \\
\hline$S$ & Someone plays with the pet every day & 78 & 82 & 74 & 67 & 31 & 59 & 87 & 53 & $<0.001^{*}$ \\
\hline$S$ & The dog's nails are trimmed & 77 & 81 & 49 & 44 & 17 & 32 & 31 & 19 & $<0.001^{*}$ \\
\hline$S$ & $\begin{array}{l}\text { Our yard is completely fenced in so that the dog cannot } \\
\text { get out, and the gate is kept closed }\end{array}$ & 59 & 62 & 79 & 73 & 32 & 60 & 88 & 55 & $0.024^{*}$ \\
\hline$S$ & The dog wears id tags & 57 & 61 & 61 & 56 & 18 & 34 & 47 & 30 & $<0.001^{*}$ \\
\hline$S$ & The dog is licensed & 48 & 51 & 42 & 39 & 15 & 28 & 33 & 21 & $<0.001^{*}$ \\
\hline$S$ & The home/yard has been changed to make it safer & 44 & 47 & 50 & 46 & 23 & 44 & 59 & 37 & 0.30 \\
\hline$S$ & The dog is spayed/neutered & 43 & 45 & 55 & 51 & 12 & 24 & 72 & 45 & 0.013 \\
\hline$S$ & When outside, kept on a chain & 37 & 39 & 44 & 40 & 36 & 68 & 61 & 38 & $0.001^{*}$ \\
\hline S & Someone pets/scratches the dog, daily & 23 & 26 & 26 & 24 & 9 & 17 & 22 & 14 & 0.68 \\
\hline$S$ & Household objects are used as toys & 23 & 25 & 26 & 24 & 12 & 23 & 37 & 23 & 0.996 \\
\hline \multirow[t]{2}{*}{ S } & The dog has an outside dog house & 18 & 19 & 69 & 63 & 43 & 81 & 87 & 54 & $<0.001^{*}$ \\
\hline & The dog spends most of its time outside the home & 15 & 16 & 67 & 63 & 41 & 77 & 134 & 84 & $<0.001^{*}$ \\
\hline
\end{tabular}

Note: S: Indicates items on Shore et al. (2006) list.

* Indicates significance at the $5 \%$ level with a Bonferroni adjustment

\section{Enriched Care}

Table 3 shows that small dogs were more likely to receive 10 or more of the 20 components of the enriched level of care-Bahamas (RCBS) than other types of dogs: small dogs (90.5\%, 86 dogs), large dogs (61.3\%, 57 dogs), pit bulls (57.4\%, 27 dogs) and potcakes (27.6\%, 40 dogs), Chi- squared $=94.2, d f=3, n=380, p<0.001$. When large dogs were compared to small dogs, they were less likely to receive 10 or more of the RCBS components, odds ratio $=0.17$, CI $[0.07$ 0.37]. Pit bulls were just as likely to receive these components of care as potcakes, odds ratio $=1.94$, CI [0.98-3.35]. A logistic regression, to see if the provision of RCBS was linked to type of dog, if 
the dog spent most of its time outside the home and if the dog was kept as a companion, found all three components to be statistically significant (type of dog: Wald statistic $=40.8, d f=3, p<$
0.001), spending most of its time outside the home: Wald statistic $=10.0, d f=1, p=0.001$, dog kept as a companion: Wald statistic $=9.5, d f=1$, $p=0.002$ )

Table 3

Enriched Care-Bahamas (RCBS) components offered different types of dogs.

\begin{tabular}{|c|c|c|c|c|c|c|c|c|c|c|}
\hline & \multirow[b]{2}{*}{ Component } & \multicolumn{2}{|c|}{ Small dogs } & \multicolumn{2}{|c|}{ Large dogs } & \multicolumn{2}{|c|}{ Pit bull } & \multicolumn{2}{|c|}{ Potcake } & \multirow{2}{*}{$\begin{array}{l}x^{2} \\
p=\end{array}$} \\
\hline & & $\mathrm{n}$ & $\%$ & $\mathrm{n}$ & $\%$ & $\mathrm{n}$ & $\%$ & $\mathrm{n}$ & $\%$ & \\
\hline $\mathrm{R}$ & The dog is bathed & 83 & 89 & 82 & 75 & 40 & 76 & 83 & 52 & $<0.001^{*}$ \\
\hline $\mathrm{R}$ & Someone buys smalls for the dog & 83 & 88 & 68 & 63 & 33 & 62 & 57 & 35 & $<0.001^{*}$ \\
\hline $\mathrm{R}$ & The dog has its own smalls & 83 & 88 & 78 & 72 & 39 & 74 & 69 & 43 & $<0.001^{*}$ \\
\hline $\mathrm{R}$ & The pet gets treats & 80 & 86 & 88 & 82 & 41 & 79 & 109 & 68 & $0.003^{*}$ \\
\hline \multirow[t]{3}{*}{$\mathrm{R}$} & Usually eats premium/special food & 79 & 85 & 78 & 72 & 44 & 83 & 89 & 56 & $<0.001^{*}$ \\
\hline & The dog is groomed & 78 & 84 & 65 & 60 & 33 & 62 & 46 & 29 & $<0.001^{*}$ \\
\hline & The dog's hair is cut & 78 & 84 & 58 & 53 & 16 & 31 & 34 & 21 & $<0.001^{*}$ \\
\hline $\mathrm{R}$ & The pet stays on someone's lap often or sometimes & 74 & 80 & 48 & 44 & 12 & 23 & 37 & 23 & $<0.001^{*}$ \\
\hline $\mathrm{R}$ & The dog is welcome to come and go, in most areas of the home & 73 & 78 & 48 & 44 & 13 & 25 & 35 & 22 & $<0.001^{*}$ \\
\hline $\mathrm{R}$ & The pet has its own bed & 70 & 75 & 34 & 32 & 20 & 38 & 45 & 28 & $<0.001^{*}$ \\
\hline $\mathrm{R}$ & The pet stays at someone's side, often or sometimes & 69 & 74 & 69 & 63 & 30 & 57 & 77 & 48 & $<0.001^{*}$ \\
\hline $\mathrm{R}$ & Is walked - every day, sometimes & 69 & 74 & 80 & 73 & 44 & 83 & 77 & 48 & $<0.001^{*}$ \\
\hline $\mathrm{R}$ & Looked for advice about the pet & 60 & 64 & 63 & 58 & 22 & 42 & 57 & 36 & $<0.001^{*}$ \\
\hline $\mathrm{R}$ & When someone exercises, the dog goes along & 58 & 62 & 60 & 56 & 39 & 74 & 68 & 43 & $<0.001^{*}$ \\
\hline $\mathrm{R}$ & The dog is included in family events & 57 & 61 & 49 & 45 & 15 & 28 & 36 & 23 & $<0.001^{*}$ \\
\hline $\mathrm{R}$ & The pet has received training & 52 & 55 & 48 & 44 & 21 & 40 & 34 & 21 & $<0.001^{*}$ \\
\hline $\mathrm{R}$ & Is alone fewer than 4 hours a day & 51 & 54 & 52 & 48 & 24 & 46 & 64 & 40 & 0.087 \\
\hline $\mathrm{R}$ & When planning a trip we look for pet friendly accommodation & 46 & 50 & 25 & 23 & 17 & 32 & 35 & 22 & $<0.001^{*}$ \\
\hline $\mathrm{R}$ & When we travel, the pet always, sometimes goes along & 32 & 34 & 20 & 18 & 5 & 9 & 16 & 10 & $<0.001^{*}$ \\
\hline $\mathrm{R}$ & The dog gets scraps from the table & 30 & 33 & 58 & 53 & 23 & 45 & 116 & 72 & $<0.001^{*}$ \\
\hline
\end{tabular}

Note: R: Indicates items on Shore et al. (2006) list.

* Indicates significance at the 5\% level with a Bonferroni adjustment

\section{Luxury Care}

Provision of luxury components of care-Bahamas (LCBS) was less common than components for ECBS, SCBS and RCBS (Table 4). Of the 15 LCBS components, relatively few dogs, irrespective of size, received eight or more of these, $8.1 \%$ of potcakes (12 dogs), $6.1 \%$ of pit bulls (3 dogs) $12.4 \%$ of large dogs (12 dogs), $17.6 \%$ (16 dogs) of small dogs (Chi-squared $=$ 6.6, $d f=3, n=385, \mathrm{p}=0.087)$. A logistic regression, to see if the provision of legal care was linked to type of dog, if the dog spent most of its time outside the home and if the dog was kept as a companion, found none of these components to be statistically significant $(p>0.05)$. 
Table 4

Luxury Care-Bahamas (LCBS) Offered Different Types of Dogs.

\begin{tabular}{|c|c|c|c|c|c|c|c|c|c|c|}
\hline & \multirow[b]{2}{*}{ Component } & \multicolumn{2}{|c|}{ Small dogs } & \multicolumn{2}{|c|}{ Large dogs } & \multicolumn{2}{|c|}{ Pit bull } & \multicolumn{2}{|c|}{ Potcake } & \multirow{2}{*}{$\begin{array}{l}X^{2} \\
p=\end{array}$} \\
\hline & & $\mathrm{n}$ & $\%$ & $\mathrm{n}$ & $\%$ & $\mathrm{n}$ & $\%$ & $\mathrm{n}$ & $\%$ & \\
\hline & The dog sleeps in household member's bedroom & 62 & 67 & 28 & 26 & 8 & 15 & 18 & 11 & $<0.001^{*}$ \\
\hline L & The pet has clothing & 57 & 62 & 24 & 22 & 4 & 8 & 15 & 9 & $<0.001^{*}$ \\
\hline L & The dog receives dental care & 49 & 52 & 47 & 43 & 22 & 42 & 35 & 22 & $<0.001^{*}$ \\
\hline L & The pet receives holiday gifts & 43 & 46 & 34 & 32 & 10 & 19 & 27 & 17 & $<0.001^{*}$ \\
\hline $\mathrm{L}$ & Someone knows dog first-aid & 43 & 46 & 34 & 32 & 10 & 19 & 27 & 17 & 0.003 \\
\hline L & The dog does agility work & 38 & 42 & 45 & 41 & 21 & 42 & 51 & 32 & 0.30 \\
\hline L & We celebrate the dog's birthday & 34 & 37 & 27 & 25 & 9 & 17 & 21 & 13 & $<0.001^{*}$ \\
\hline L & The dog is taken to events for dogs & 26 & 28 & 15 & 14 & 10 & 19 & 17 & 11 & 0.005 \\
\hline$L$ & Someone makes smalls for the dog & 24 & 26 & 19 & 17 & 4 & 8 & 18 & 11 & 0.003 \\
\hline $\mathrm{L}$ & The dog goes to day care & 16 & 17 & 8 & 7 & 4 & 8 & 10 & 6 & 0.053 \\
\hline $\mathrm{L}$ & There is a dog door & 16 & 17 & 14 & 13 & 8 & 15 & 11 & 7 & 0.076 \\
\hline L & The pet has a microchip & 16 & 17 & 7 & 6 & 1 & 2 & 14 & 9 & 0.021 \\
\hline L & The dog has problem solving smalls & 14 & 15 & 15 & 14 & 7 & 13 & 14 & 9 & 0.42 \\
\hline L & The dog is in someone's will & 14 & 15 & 6 & 6 & 4 & 8 & 7 & 4 & 0.033 \\
\hline L & We have animal health insurance & 13 & 14 & 15 & 14 & 4 & 8 & 14 & 9 & 0.35 \\
\hline $\mathrm{L}$ & We own DVDs to entertain the dog & 12 & 13 & 10 & 9 & 3 & 6 & 11 & 7 & 0.41 \\
\hline
\end{tabular}

Note: L: Indicates items on Shore's et al. (2006) list.

* Indicates significance at the $5 \%$ level with a Bonferroni adjustment

\section{Interactions with dogs}

While the use of violence to discipline dogs, when they did something wrong or in training, was common to all types of dogs, other interactions showed little variation between the types of dogs (Table 5). While large dogs were just as likely to be teased in training as small dogs, odds ratio =
0.95, CI [0.44-2.07], however, pit bulls were more likely than potcakes to be teased, odds ratio = 3.63, CI [1.82-7.23]. Overall, the percentage of dogs not harmed at all (23.1\%) was similar for each type of dog (Chi-squared $=1.33, d f=3, n=$ 424, $p=0.72$ ).

Table 5

Interaction Between Caregivers and Dogs.

\begin{tabular}{|c|c|c|c|c|c|c|c|c|c|}
\hline \multirow[b]{2}{*}{ Treatment of the dog } & \multicolumn{2}{|c|}{ Small dogs } & \multicolumn{2}{|c|}{ Large dogs } & \multicolumn{2}{|c|}{ Pit bull } & \multicolumn{2}{|c|}{ Potcake } & \multirow{2}{*}{$\begin{array}{l}X^{2} \\
p=\end{array}$} \\
\hline & $\mathrm{n}$ & $\%$ & $\mathrm{n}$ & $\%$ & $\mathrm{n}$ & $\%$ & $\mathrm{n}$ & $\%$ & \\
\hline The dog is hit when it does something wrong & 50 & 54 & 55 & 51 & 26 & 49 & 85 & 53 & 0.73 \\
\hline Sometimes household members annoy the dog & 31 & 33 & 36 & 33 & 12 & 23 & 61 & 38 & 0.24 \\
\hline The dog is slapped when it is being trained & 24 & 26 & 27 & 25 & 20 & 39 & 32 & 20 & 0.070 \\
\hline The dog is teased in training & 15 & 16 & 15 & 14 & 22 & 42 & 26 & 16 & $<0.001^{*}$ \\
\hline $\begin{array}{l}\text { Household members sometimes kick or throw hard objects at } \\
\text { the dog }\end{array}$ & 11 & 12 & 24 & 22 & 14 & 26 & 44 & 27 & 0.056 \\
\hline A household member has physically injured the dog & 9 & 10 & 4 & 4 & 4 & 8 & 20 & 13 & 0.118 \\
\hline
\end{tabular}


Table 6 illustrates factors which may influence the care of dogs for different types of dog. Potcakes were least likely to have been bought $(20.3 \%$ or 32 respondents) and small dogs appeared to be the dog of choice of first-time caregivers $(46.9 \%$ or 46 respondents). While most dogs had names, pit bulls and potcakes were less likely to be considered members of the household than large or small dogs and more likely to be kept outside the home. Potcakes were most likely to be ignored much of the time. Domestic violence was most common in households with pit bulls (43\% or 23 respondent homes) and potcakes ( $40 \%$ or 64 respondents). Respondents who reported on pit bulls were more likely than other respondents to report that previous dogs in the household had been relinquished for behavioural reasons.

\section{Table 6}

Factors Which May Influence the Care of the Dog in the Household

\begin{tabular}{|c|c|c|c|c|c|c|c|c|c|}
\hline \multirow[b]{2}{*}{ Integration of the dog into the household } & \multicolumn{2}{|c|}{ Small dogs } & \multicolumn{2}{|c|}{ Large dogs } & \multicolumn{2}{|c|}{ Pit bull } & \multicolumn{2}{|c|}{ Potcake } & \multirow{2}{*}{$\frac{X^{2}}{p}=$} \\
\hline & $\mathrm{n}$ & $\%$ & $\mathrm{n}$ & $\%$ & $\mathrm{n}$ & $\%$ & $\mathrm{n}$ & $\%$ & \\
\hline The dog has a name & 90 & 97 & 103 & 95 & 49 & 94 & 142 & 88 & 0.035 \\
\hline The dog is considered a member of the household & 84 & 89 & 86 & 79 & 38 & 72 & 99 & 62 & $<0.001^{*}$ \\
\hline We bought this dog & 61 & 67 & 67 & 62 & 33 & 65 & 32 & 20 & $<0.001^{*}$ \\
\hline There is a particular person who looks after the dog each day & 60 & 65 & 63 & 58 & 35 & 66 & 80 & 50 & 0.062 \\
\hline This is the first dog the household has had & 46 & 47 & 35 & 32 & 12 & 23 & 55 & 34 & 0.017 \\
\hline Domestic violence in the household & 19 & 19 & 28 & 29 & 23 & 43 & 64 & 40 & $0.002^{*}$ \\
\hline The dog spends most of its time outside the home & 17 & 17 & 65 & 65 & 41 & 77 & 134 & 84 & $<0.001$ \\
\hline The dog is ignored much of the time & 14 & 15 & 20 & 19 & 16 & 21 & 58 & 36 & $<0.001^{*}$ \\
\hline $\begin{array}{l}\text { We had to give away a previous dog because it was badly } \\
\text { behaved }\end{array}$ & 12 & 13 & 14 & 13 & 12 & 23 & 22 & 14 & 0.32 \\
\hline The dog is ignored by the majority of the household & 5 & 5 & 20 & 18 & 14 & 26 & 44 & 27 & $<0.001^{*}$ \\
\hline
\end{tabular}

Note: * Indicates significance at the $5 \%$ level with a Bonferroni adjustment

Table 7 reports on the reasons for keeping a dog. Few dogs (less than 24\%), of any type, were kept for the benefits which can accrue to caregivers; only one respondent indicated that one or more pit bulls were kept for the health of a family member. Small dogs were most likely to be kept as companions (71.4\% or 70 respondents) and least likely as protectors of households, in contrast to large dogs (53.9\% or 55 respondents) or pit bulls (67.9\% or 36 respondents). Few dogs (less than $14 \%)$, of any type, participated in organized dog fights. Pit bulls were the most likely type of dog to be kept for breeding.

Table 7

Reasons for Keeping the Dog

\begin{tabular}{|c|c|c|c|c|c|c|c|c|c|}
\hline & \multicolumn{2}{|c|}{ Small dogs } & \multicolumn{2}{|c|}{ Large dogs } & \multicolumn{2}{|c|}{ Pit bull } & \multicolumn{2}{|c|}{ Potcake } & \multirow{2}{*}{$\begin{array}{c}X^{2} \\
p=\end{array}$} \\
\hline & $\mathrm{n}$ & $\%$ & $\mathrm{n}$ & $\%$ & $\mathrm{n}$ & $\%$ & $\mathrm{n}$ & $\%$ & \\
\hline $\begin{array}{l}\text { The main reason for having this dog is to be a companion } \\
\text { to a household member }\end{array}$ & 70 & 71 & 66 & 64 & 26 & 50 & 70 & 44 & $<0.001^{*}$ \\
\hline The dog is kept to improve the health of a family member & 21 & 22 & 23 & 22 & 1 & 2 & 22 & 21 & $0.001^{*}$ \\
\hline The main reason for having the dog is to protect the home & 19 & 19 & 55 & 54 & 36 & 68 & 102 & 64 & $<0.001^{*}$ \\
\hline We breed this dog in order to sell the puppies & 18 & 19 & 14 & 13 & 19 & 36 & 11 & 7 & $<0.001^{*}$ \\
\hline The dog participates in organized fights & 11 & 12 & 2 & 2 & 7 & 13 & 11 & 7 & 0.026 \\
\hline
\end{tabular}

Note: * Indicates significance at the $5 \%$ level with a Bonferroni adjustment 
Many respondents considered their dogs well cared for and well behaved (Table 8) but respondents were least likely to consider that potcakes were well cared for: odds ratio (potcakes vs. small dogs, well cared for) 0.15 , CI [0.050.42]. Only two of 38 dogs aged one or less were reported as being not well cared for whereas $14.8 \%$ (56 dogs) of those aged over one were reported as not well cared for. Dogs kept as companions were equally likely to be considered

Table 8

Respondent's Opinion of Dogs' Welfare.

\begin{tabular}{lrrrrrrrrrrr}
\hline & \multicolumn{1}{c}{ Small dogs } & \multicolumn{1}{c}{ Large dogs } & Pit bull & Potcake & $X^{2}$ \\
\hline Respondents' opinion of dog's welfare & $\mathrm{n}$ & $\%$ & $\mathrm{n}$ & $\%$ & $\mathrm{n}$ & $\%$ & $\mathrm{n}$ & $\%$ & $\mathrm{p}=$ \\
\hline Dog is well cared for & 90 & 96 & 98 & 89 & 46 & 89 & 126 & 78 & $<0.001^{*}$ \\
The dog is generally well behaved & 82 & 89 & 98 & 89 & 45 & 85 & 127 & 79 & 0.086 \\
Dog is abused & 7 & 7 & 9 & 8 & 4 & 8 & 25 & 16 & 0.102 \\
\hline
\end{tabular}

Note: * Indicates significance at the $5 \%$ level with a Bonferroni adjustment

\section{Perception of care}

Across all dog types, respondent's perceptions of what constitutes well cared for were examined in relation to the legal components of care which are food, water and shelter. Well cared for was associated with each of these components: Fisher's exact test: $p=0.01, n=454 ; p<0.001, n$ $=470 ; p<0.001, n=468$, respectively, as was having a veterinarian, Fisher's exact test: $p<$ 0.001, $n=465$; ignoring the dog, Fisher's exact test: $p<0.001, n=468$; or physically injuring the dog, Fisher's exact test: $p<0.001, n=462$. However, leaving the dog on its own for four hours or more a day was not seen to be linked to well cared for, Fisher's exact test: $p=0.41, n=$ 466 respectively. Overall, the respondents' perceptions of well cared for are grounded in aspects of care which would be important to the physical wellbeing of the pet.

\section{Discussion}

\section{Limitations of the study}

The target population was college students and so the replies may not reflect the care given dogs in the wider population. However, as the results were broadly in keeping with those of Fielding and Plumridge (2005) and Fielding (2007), they may not be unique to college students. Size and age of dog were confounded in this data set due to the limited number of dogs whose ages were well cared for across all types of dog, Chi-squared $=5.75, d f=3, p=0.13, n=228$, but when dogs were not kept as companions, potcakes were least likely to be considered as well cared for $(74.2 \%$, 66 dogs) and small dogs the most likely (96.4\%, 27 dogs), Chi-squared $=9.70, d f=3, p=0.021, n$ $=180$. Relatively few dogs were reported as abused, but potcakes had a higher rate of abuse compared with all the other types of dog (Fisher's exact test, $p=0.022, n=408$ ). reported, so our data cannot be used to tease out size and age differences with respect to care, but as the average ages of the different types of dog were similar, this may not be an important consideration.

\section{Cultural considerations and care}

The care of dogs is modified by cultural factors (Matter \& Daniels, 2000) and whether caregivers are living in urban or rural areas (e.g., Baranyiová, Holub, Tyrlík, Janáâková \& Ernstová, 2005 and Ortega-Pacheco et al., 2007). Therefore, when interpreting these results we must be mindful that our target population predominantly lived in an urban setting in a sub-tropical environment of a small island developing state dominated by AfroCaribbean residents. Hore (2005) has shown that attachment influences the level of care offered pets as well as where pets are typically keptinside the home or in the yard (Shore et al., 2006). Bahamians are less attached to their pets than caregivers in the United States (Fielding, 2008). In The Bahamas, dogs are typically kept for protection; many are kept outside the home and receive limited health care (Fielding \& Plumridge, 2005). All these local aspects of dog keeping can, therefore, be expected to influence the level of care offered dogs.

As might have been expected, the frequency with 
which components of care beyond those of ECBS decreased from SCBS, RCBS to a minority of dogs receiving LCBS. Of concern is the difference in the frequency with which legal components of care were offered different types of dogs, and the fact that not all dogs received all these components. Again, potcakes were found to receive the least care, a finding consistent with that of Fielding and Plumridge (2005), and the current study shows areas in which they might be at higher risk of neglect than other types of dog.

These findings suggest that many dogs may be suffering from neglect. Neglect is typically the most common harm inflicted upon dogs in The Bahamas (Fielding et al., 2005) and this lack of care suggests that there is room for increased enforcement of the laws concerning animal welfare. Further, the use of violence against dogs has been found to be common; Fielding and Plumridge (2008) have also shown that it is common and often acceptable to household members.

My conversations with college students suggest that many caregivers are unaware of non-violent ways of training dogs. This is another area of concern regarding dog welfare. Such attitudes may reflect the use of violence to discipline Bahamian children (Brennen, Carroll, Fielding, Miller, Adderley, \& Thompson, 2010), and an old- fashioned attitude toward dog training (Lindsay, 2001). Moreover, pit bulls were most likely to be teased in training. This is consistent with the idea that pit bulls are abused when trained to make then bad (Burrows et al, 2004, p. 45). The possibility of this being detrimental to society has been seen in the United Kingdom ("London dog attack murderer jailed for life", 2010).

\section{Size of dogs}

The findings from this study support the idea that the size of the dog is important in determining the level of care offered. The importance of the association between the size/type of dog and level of care was the only consistent factor in the logistic regression for all but luxury care (which was rarely provided). This observation is consistent with other studies, e.g. Masters and McGreevy (2008), which have reported differences in the animal-human interaction which are dependent upon the size of the dog. However, Kobelt, Hemsworth, Barnett and Colman (2003) found that large dogs were more likely to be trained than small dogs, which is the opposite of what is found here.

We suggest that the reason small dogs receive more care than other types of dog in this study is that they are probably perceived as in need of more care than large dogs. Large dogs may be perceived as being better able to care for themselves outside the home than small dogs. Small dogs may be viewed as analogous to puppies which never grow up, a visible neonatal trait, and this may encourage caregivers to allow them inside the home. This may be an example of anthropomorphism which is beneficial to pets (Serpell, 2003). In The Bahamas, while puppies are tolerated inside the home, when they reach a certain size they are often relegated to the yard and no longer allowed inside the home. Consequently, the bonds between caregivers and large dogs can get strained through the lack of interaction and shared space. This limited interaction probably results in less interest in the dog and ultimately less care. This size-based interaction may also be the reason more small dogs than large dogs were given obedience training.

Shore (2005) found that the size of the dog was sometimes a factor involved in failed adoptions and Diesel, Pfeiffer, and Brodbelt (2008) also noted that large dogs were at greater risk of being re-homed:

larger dogs require more exercise, they are more expensive to keep and can cause more damage than smaller dogs if they have destructive tendencies and what appears a small problem with a smaller dog can be quite a big problem in a larger dog and more difficult to control (p. 237).

Comments from college students echo this view. Different care is offered younger and older dogs and this may be due to their increasing size; consequently, as dogs get larger they are subject to a limited form of relinquishment or limited abandonment; a separation rather than a divorce. Banishing dogs from the home, with an associated reduction of care may be a way of removing unwanted animals from the household without 
going as far as abandoning them or handing them to the shelter, where they may be euthanized -a fate which many people in The Bahamas find acceptable only if dogs are sick (Fielding et al., 2005).

A study by Weng, Kass, Hart, and Chomel (2006) found that pets acquired as puppies are more likely to be relinquished and Miller, Staats, Partlo, and Rada (1996) found that puppies in general were at higher risk of being relinquished. In this study, respondents reported on dogs typically aged three years old, so puppy-related problems were probably not considered by participants.

\section{Inside and outside dogs}

Once dogs are allowed inside the home, more opportunities exist for interaction and bonding to take place between caregivers and dogs. This is important as a study by Alie, Davis, Fielding, and Maldonado (2007) in the Caribbean highlighted the lack of interaction and passive ownership, as opposed to active ownership and positive interactions between pet and caregiver. Where the dog spent most of its time (inside or outside the home) was also related to the level of care it received.

In The Bahamas, there is a distinction between inside and outside dogs. Some household members do not like having large dogs inside the home as they are considered to take up too much space or be a threat to children. Small dogs are more likely to be tolerated inside the home as they may be considered less threatening, even though all dogs bite and, as documented by Sacks, Sinclair, Gilchrist, Golab and Lockwood (2000) many breeds have killed humans. This fear of teeth and the subsequent keeping of the dog outside were described by a college student:

When they were puppies, they were inside and they got the can[ned] food. And then they grew teeth and all that; they graduated outside and they had a doghouse and we give them scrap food from the food store. And they would eat what we eat; the scraps, with bones and all that (Butler et al., 2001, pp. 15-16).

Reasons for keeping dogs

Relatively few dogs were kept as companion animals; but this reason was related to the level of standard or enriched care offered. The reason for keeping dogs was related to the type of dog and also the level of care offered. Pit bulls and potcakes were least likely to be kept as companions and most likely to be kept for protection. This differentiation between working and companion dogs put these dogs at higher risk of being treated in ways which may give cause for concern, such as teasing. Generally, respondents seem not to appreciate the benefits described by Beck and Katcher (1996) which can arise from keeping dogs. This may be an issue which reflects the overall lack of knowledge about pet keeping (Fielding, 2007) and so is an area where education and changes to societal norms would benefit both pets and caregivers.

The fact that small dogs appear to be the dogs of choice for first-time dog keepers suggests that there may be a move from keeping large dogs to keeping small ones; a similar change in the popularity of small dogs in Australia noted by Kobelt et al. (2003). This study cannot explain why this may be, however, possible explanations include: changes in accommodation patterns from homes with larger to smaller yards, or none at all, as in a condominium setting, fashion, availability etc. A review of advertisements in one Bahamian newspaper for a two-month period (JanuaryMarch 2010) indicated that of the 68 distinct advertisements, $41.2 \%$ were for small dogs, and $26.5 \%$ for pit bulls. The overall welfare offered to the dog population could be expected to improve if this trend continues. If people are choosing small dogs in response to changes in housing, this may be another example of changing dog keeping practices associated with increasing urbanization (Baranyiová et al., 2005).

\section{Pit bulls}

A sufficient number of pit bulls were reported on to allow them to be considered separately. Their care is of local importance as they are considered to be the most popular pure-breed dog (Fielding \& Plumridge, 2005) although the Bahamas Kennel Club does not recognise it as a pedigree dog. Pit bulls are the dogs most commonly bred for commercial gain (Fielding, 2010, and a finding repeated here) and is the breed implicated in all the fatal dog attacks on humans in The Bahamas to date (Burrows et al., 2004). In many aspects, the care offered pit bulls is little different from that offered potcakes. If it is agreed that potcakes 
are at risk of neglect, then so may pit bulls. Their treatment (slapping and teasing) suggests that they may, as indicated by Burrows \& Fielding (2005), indeed be at risk of being abused animals. Respondents who reported owning a pit bull were more likely to live in a home with domestic violence. This finding could suggest that pit bull caregivers themselves may be potential victims of abuse. In The Bahamas, as elsewhere, domestic violence is part of a package of deviant behaviours (e.g., Fielding \& Plumridge, 2010; McPhedran, 2009) which can include harm to pets. Our finding is consistent with Barnes, Boat, Putnam, Dates, and Mahlman's 2006 study which found that people who kept vicious dogs were more likely to commit deviant behaviours.

While small dogs received better care overall, the use of violence on dogs was similar, irrespective of size. The use of violence and other harmful acts against pit bulls and other dogs, indicated that all types of dog were at risk of being abused. Society holds caregivers responsible for the actions of their dogs (Burrows \& Fielding, 2005) so if caregivers will not voluntarily care for their pets in an acceptable way, regulations need to be enforced to protect society from potentially abused dogs.

The observation that homes with pit bulls were at higher risk of being those with domestic violence may suggest that pit bulls could be a flag for investigating undesirable behaviours in homes. This suggestion may be controversial, and open to claims of profiling. Clearly, more work needs to be done on this sensitive issue. As Fielding and Ostburg (2008) have found that pit bulls are a popular dog throughout the Caribbean, this matter may be of importance beyond New Providence. These findings may have implications concerning the on-going international debate concerning breed-specific legislation and the individuals who choose to keep certain types of dog (e.g., Bennetto \& Herbert, 2007), particularly if these findings are replicated in other communities.

\section{REFERENCES}

Alie, K., Davis, B. W., Fielding, W. J., \& Maldonado, F. G. (2007). Attitudes towards dogs and other "pets" in Roseau, Dominica. Anthrozoös, 20, 143154. doi:10.2752/175303707X207936
Perception of well cared for

Respondents' perceptions as to what constituted well cared for and not well cared for appeared to be grounded in components of care which would be required for the pet to thrive. Irrespective of the level of care actually offered, respondents had a generally high perception of it. This probably reflects their differences in expectations as to what constitutes adequate care. These differences may be associated with the type of dog kept. Fielding et al. (2005) reported that some people were unwilling to provide health care for potcakes, possibly because potcakes were considered to be adapted to the environment and so did not require health care. This suggests that some people do not fully appreciate what is expected of them as caregivers as they seem unaware that dogs benefit from being provided physical necessities and a stimulating environment (Horwitz, 2007). These aspects of care exceed the provision of merely legal care and a local perception of the level of care dogs need ("All dogs need is food and shelter”, 2006).

\section{Future directions}

Future research would benefit from the use of longitudinal studies, or cohorts of puppies of different breeds to observe how their care changes as the dogs develop and the circumstances under which puppies are kept outside of the home as they grow. The reasons for choosing different types of dogs and other mediating circumstances of the household could be examined to observe how these influence care. In addition, the personality characteristics of caregivers could be explored to examine whether Bahamian caregivers who select small dogs are different from those who choose other dogs. The caregiver's perception of abuse, well behaved and trained needs to be further investigated to understand what these mean within this community.

All dogs need is food and shelter (2006, January 23). [Letter to the editor]. The Tribune. p 4.

Ascione, F. R. (Ed.). (2008). The international handbook on animal abuse and cruelty: Theory, research, and application. West Lafayette, IN: Purdue University Press. 
Ascione, F. R., \& Arkow, P. (Eds.). (1999). Child abuse, domestic violence, and animal abuse: Linking the circles of compassion for prevention and intervention. West Lafayette, IN: Purdue University Press.

Baranyiová, E, Holub, A., Tyrlík, M., Janáâková, B., \& Ernstová, M. (2005). The influence of urbanization on the behaviour of dogs in the Czech Republic. Acta Veterinaria Brno, 74, 401-409.

Barnes, J. E., Boat, B. W., Putnam, F. W., Dates, H. F., \& Mahlman, A. R. (2006). Ownership of high-risk ("vicious") dogs as a marker for deviant behaviors: Implications for risk assessment. Journal of Interpersonal Violence, 21, 1616-1634. doi:10.1177/0886260506294241

Beck, A., \& Katcher, A. (1996). Between pets and people: The importance of animal companionship. West Lafayette, IN: Purdue University Press.

Bennetto, J., \& Herbert, I. (2007, January 13). Dangerous Dogs Act has never worked, says RSPCA. The Independent. Retrieved from http://www.independent.co.uk/news/uk/crime/dang erous-dogs-act-has-never-worked-says-rspca431905.html

Brennen, S., Fielding, W. J., Carroll, M. C., McCants Miller, J. C., Adderley, L., \& Thompson, M. A. (2010). A preliminary investigation of the prevalence of corporal punishment of children and selected co-occurring behaviours in households on New Providence, The Bahamas. The International Journal of Bahamian Studies, 16, 39-56. Retrieved from http://researchjournal.cob.edu.bs

Burrows, T. J., \& Fielding, W. J. (2005). Views of college students on pit bull "ownership", New Providence, The Bahamas. Society and Animals, 13, 49-62. doi:10.1163/1568530054300163

Burrows, T. J., Fielding, W. J., \& Mather, J. (2004). Perceptions of pit bull care after three fatal dog attacks. Bahamas Journal of Science, 12 (1), 39-46.

Butler, F., Carole, C., Samuels, D., \& Vanderpool, J. (2001). [Focus group B with College of The Bahamas students on "what is a pet?”]. Unpublished raw data.

Delise, K. (2002). Fatal dog attacks: The stories behind the numbers. Manorville, NY: Anubis Press.

DeViney, E., Dickert, J., \& Lockwood, R. (1983). The care of pets within child abusing families. International Journal for the Study of Animal Problems, 4, 321-329.
Diesel, G., Pfeiffer, D. U., \& Brodbelt, D. (2008). Factors affecting the success of rehoming dogs in the UK during 2005. Preventive Veterinary Medicine, 84, 228-241. doi:10.1016/j.prevetmed.2007.12.004

Dog License Act, 1942, [CH. 378], (Bahamas). Retrieved from http://laws.bahamas.gov.bs/statutes/statute_CHAPT ER_378.html

The Dogs Registration and Control Act, 2006, [CH. 12], (Antigua and Barbuda). Retrieved from http://laws.gov.ag/acts/2006/a2006-12.pdf

Fielding, W. J. (2007). Knowledge of the welfare of non-human animals and prevalence of dog care practices in New Providence, The Bahamas. Journal of Applied Animal Welfare Science, 10(2), 153-168. doi:10.1080/10888700701313587

Fielding, W. J. (2010). Dog breeding in New Providence, The Bahamas and its potential impact on the roaming dog population I: Planned and accidental. Journal of Applied Animal Welfare Science 13, 1-13. doi: 10.1080/10888705.2010.483881

Fielding, W. J. (2010). Domestic violence and dog care in New Providence, The Bahamas. Society and Animals 118, 183-203. doi: 10.1163/156853010X492024

Fielding, W. J., \& Ostberg, A. (2008). Animal welfare in the wider Caribbean in 2008, with emphasis on dogs. Concord, NH: The Pegasus Foundation. Retrieved from http://www.caribbeananimalwelfare.org/images/Re port-

Animal_Welfare_Organizations_Survey_CAWC08 .pdf

Fielding, W. J., \& Plumridge, S. J. (2010). The association between pet care and deviant household behaviors in an Afro-Caribbean, college student community in New Providence, The Bahamas Anthrozoös 23, 69-78. doi: 10.2752/175303710X12627079939224

Fielding, W. J., \& Plumridge, S. J. (2005). Characteristics of owned dogs on the island of New Providence, The Bahamas. Journal of Applied Animal Welfare Science, 8, 245-260. doi:10.1207/s15327604jaws0804_2

Fielding, W. J., \& Plumridge, S. J. (2008, November). The link between domestic violence and animal care. Paper presented at the Research Edge Forum, The College of The Bahamas, Nassau, Bahamas. 
Fielding, W. J., Mather, J., \& Issacs, M. (2005). Potcakes: Dog ownership in New Providence, the Bahamas. West Lafayette, IN: Purdue University Press.

Horwitz, D. F. (2007). Environmental enrichment for dogs \& cats. Clinician's brief. Retrieved from http://www.cliniciansbrief.com/?p=articles\&newsid $=145$.

Kobelt, A. J. Hemsworth' P. H., Barnett, J. L., \& Coleman, G. J. (2003). A survey of dog ownership in suburban Australia: Conditions and behaviour problems. Applied Animal Behaviour Science, 82(2), 137-148. doi:10.1016/S01681591(03)00062-5

Lindsay, S. R. (2001). Handbook of applied dog behavior and training: Vol. 2. Etiology and assessment of behavior problems. Ames, Iowa: Iowa State University Press

London dog attack murderer jailed for life. (2010, March 19). BBC News. Retrieved from http://news.bbc.co.uk/2/hi/uk_news/england/london /8575766.stm

Macpherson, C. N. L., Meslin, F. X., \& Wandeler, A. I. (Eds.). (2000). Dogs, zoonoses and public health. Wallingford, England: CABI Publishing.

Masters, A. M., \& McGreevy, P. D. (2008). Dogkeeping practices as reported by readers of an Australian dog enthusiast magazine. Australian Veterinary Journal, 86(1/2), 18-26. doi:10.1111/j.1751-0813.2007.00248.x

Matter, H. C., \& Daniels, T. J. (2000). Dog ecology and population biology. In: C. N. L. Macpherson, F. X. Meslin, \& A. I. Wandeler (Eds.), Dogs, zoonoses and public health (pp. 17-62). Wallingford, England: CABI Publishing.

McPhedran, S. (2009). Animal abuse, family violence, and child wellbeing: A review. Journal of Family Violence, 24, 41-52. doi:10.1007/s10896-0089206-3

Morrow-Howell, N., Proctor, E. K., \& Dore, P. (1998). Adequacy of care: The concept and its measurement. Research on Social Work Practice, 8(1), 86-102. doi:10.1177/104973159800800107

Ortega-Pacheco, A., Rodriguez-Buenfil, C., BolioGonzalez, M. N., Sauri-Arceo, C. H., JiménezCoello, M., \& Forsberg, C. L. (2007). A survey of dog populations in urban and rural areas of
Yucatan, Mexico. Anthrozoös, 20, 261-274. doi:10.2752/089279307X224809

Penal Code, 1927, [CH. 84], (Bahamas). Retrieved from

http://laws.bahamas.gov.bs/statutes/statute_CHAPT ER_84.html\#Ch84s223

Poss, J. E., \& Bader, J. O. (2007). Attitudes toward companion animals among Hispanic residents of a Texas border community. Journal of Applied Animal Welfare Science, 10(3), 243-253. doi:10.1080/10888700701353717

Sacks, J. J., Sinclair, L., Gilchrist, J., Golab, G. C., \& Lockwood, R. (2000). Breeds of dogs involved in fatal human attacks in the United States between 1979 and 1998. Journal of the American Medical Association, 217, 836-840. doi:10.2460/javma.2000.217.836

Serpell, J. A. (2003). Anthropomorphism and anthropomorphic selection: Beyond the "cute response”. Society \& Animals, 11, 83-100. doi:10.1163/156853002320936926

Sherin, K. M., Sinacore, J. M., Li, X., Zitter, R. E., \& Shakil, A. (1998). HITS: A short domestic violence screening tool for use in a family practice setting. Family Medicine, 30(7), 508-512. Retrieved from http://www.stfm.org/fmhub/FULLPDF/JULYAUG 98/cram1.pdf

Shore, E. R. (2005). Returning a recently adopted companion animal: Adopters' reasons for and reactions to the failed adoption experience. Journal of Applied Animal Welfare Science, 8, 187-198. doi:10.1207/s15327604jaws0803_3

Shore, E. R., Riley, M. L., \& Douglas, D. K. (2006). Pet behaviors and attachment to yard verses house dogs. Anthrozoös, 19, 325-334. doi:10.2752/089279306785415466

Twining, H., Arluke, A., \& Patronek, G. (2001). Managing stigma of outlaw breeds: A case study of pit bull owners. Society and Animals, 8, 1-28. doi:10.1163/156853000X00020

Weng, H., Kass, P. H., Hart, L. A., \& Chomel, B. B. (2006). Risk factors for unsuccessful dog ownership: An epidemiological study in Taiwan. Preventative Veterinary Medicine, 77, 82-95. doi:10.1016/j.prevetmed.2006.06.004 